\title{
Introduction to the Groningen static reservoir model
}

\author{
Clemens A. Visser* \& Jose L. Solano Viota
}

Nederlandse Aardolie Maatschappij BV, Assen, the Netherlands

* Corresponding author. Email: clemens.visser@shell.com

Manuscript received: 26 June 2017, accepted: 7 September 2017

\section{Abstract}

The assessment of the seismic hazard and risk associated with the extraction of gas from the Groningen field involves a chain of modelling efforts. The first step is a description of the 3D distribution of reservoir properties in the reservoir - the static reservoir model - and is the subject of this paper. Consecutive steps in the chain of models are described elsewhere in this volume. The construction of a static reservoir model is not strictly a scientific endeavour, but many of the applied modelling techniques are underpinned by extensive scientific research. This paper aims to give a general introduction to the approach followed by NAM to build static models for the Groningen field. More detailed accounts of the applied modelling techniques, the assessment of associated uncertainties or the usage of multiple modelling scenarios are beyond the scope of the current paper, but are referenced in the text.

\section{General introduction}

A reservoir model is a computer representation of a subsurface gas, oil or water reservoir that can be used to study the distribution of reservoir properties and the flow behaviour of contained fluids. The objective is to make an accurate volumetric assessment of the reservoir, which forms the basis for a field development plan. A distinction is commonly made between static and dynamic models.

A static reservoir model uses geological concepts to describe the architecture of fluid flow pathways and barriers in the reservoir, the presence and properties of dissecting faults, the character of the pore system, and the composition of fluids and cements in the pores. The geological concept itself, i.e. the geological setting of the Groningen field, is described in a separate paper in this issue (de Jager \& Visser, 2017).

A dynamic reservoir model uses the static model as a framework, but serves to describe the transport processes of pore fluids through the reservoir as a function of a pressure gradient exerted on the reservoir. Dynamic models are calibrated (or history-matched) with historical field production data. They are used to forecast future production within given constraints such as production licences and facilities. In the context of production-induced seismicity, the dynamic model assesses the expected pressure depletion resulting from the offtake of gas. The pressure depletion is input in geomechanical models for cal- culating the associated reservoir compaction, which is thought to be the source for the energy that is released via induced seismicity. Following this chain of consecutive modelling steps, the consequences of different production scenarios in terms of induced seismicity and seismic hazard can be compared. This is extensively treated in other contributions in this issue.

The current paper describes the current generation of static models of the Groningen field. A separate paper focuses on the dynamic model (Van Oeveren et al., 2017).

\section{History of static modelling in Groningen}

Reservoir models are generally based on observations at drilled wells which are interpolated between the well locations. The interpolation can be steered by other sources of information such as seismic data or geological concepts. The level of detail that can be achieved depends on the amount and quality of available input data, and on the specifications of the available modelling tools.

Only a few wells were drilled in the early days of appraisal and development of the Groningen field. Poor-quality seismic data were available from a limited number of 2D seismic surveys. Figure 1 shows a very early model in the form of an interpreted top_reservoir structural map, compiled shortly after the drilling of the Slochteren-1 discovery well in 1959. Note that at that

(C) Netherlands Journal of Geosciences Foundation 2018. This is an Open Access article, distributed under the terms of the Creative Commons Attribution-NonCommercial-NoDerivatives licence (http://creativecommons.org/licenses/by-nc-nd/4.0/), which permits noncommercial re-use, distribution, and reproduction in any medium, provided the original work is unaltered and is properly cited. The written permission of Cambridge University Press must be obtained for commercial re-use or in order to create a derivative work. 


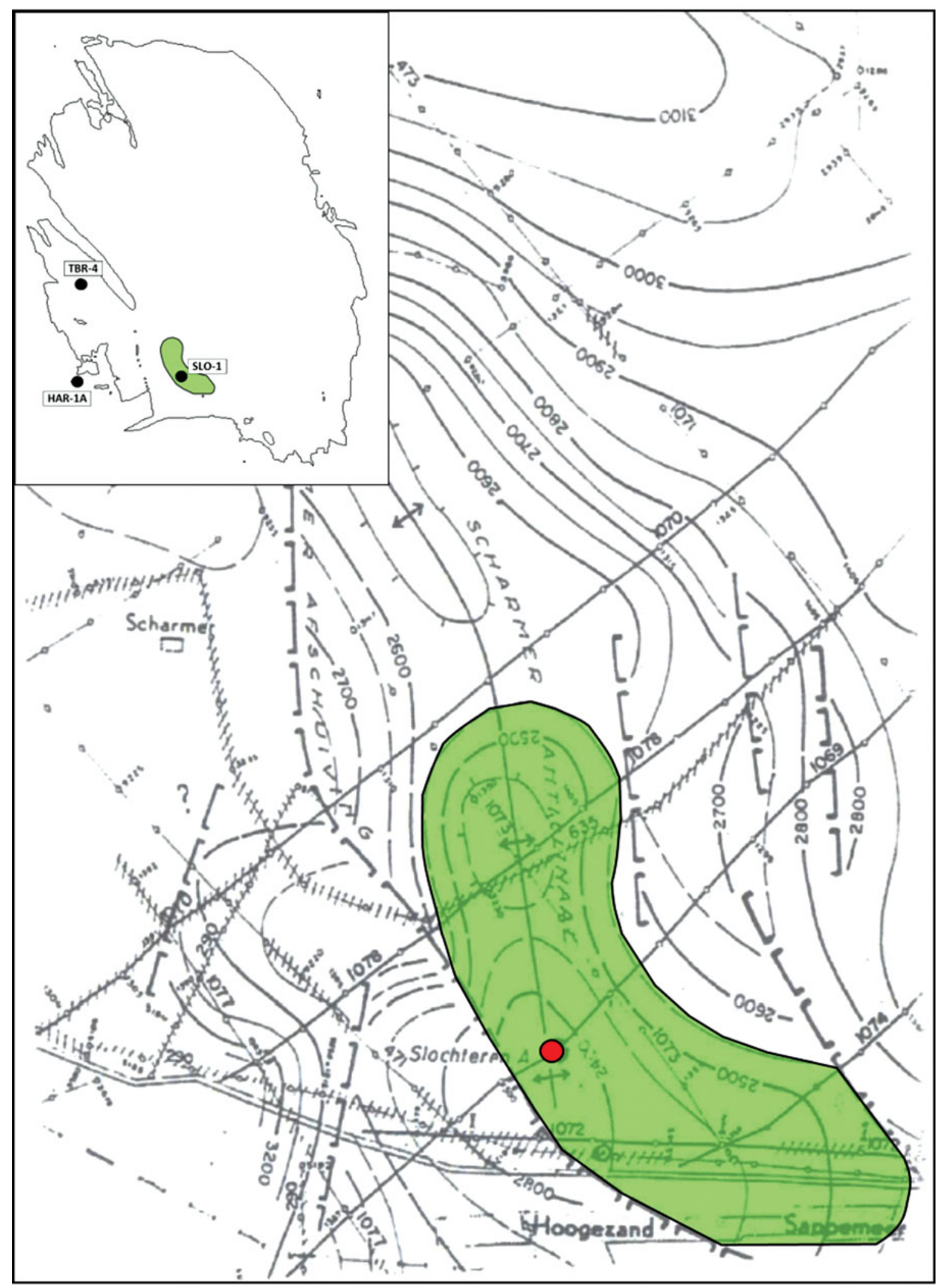

Fig. 1. Structural map of the Groningen field prepared for an internal NAM document in 1959. Note the limited extent of the map area compared to the inset location map. 


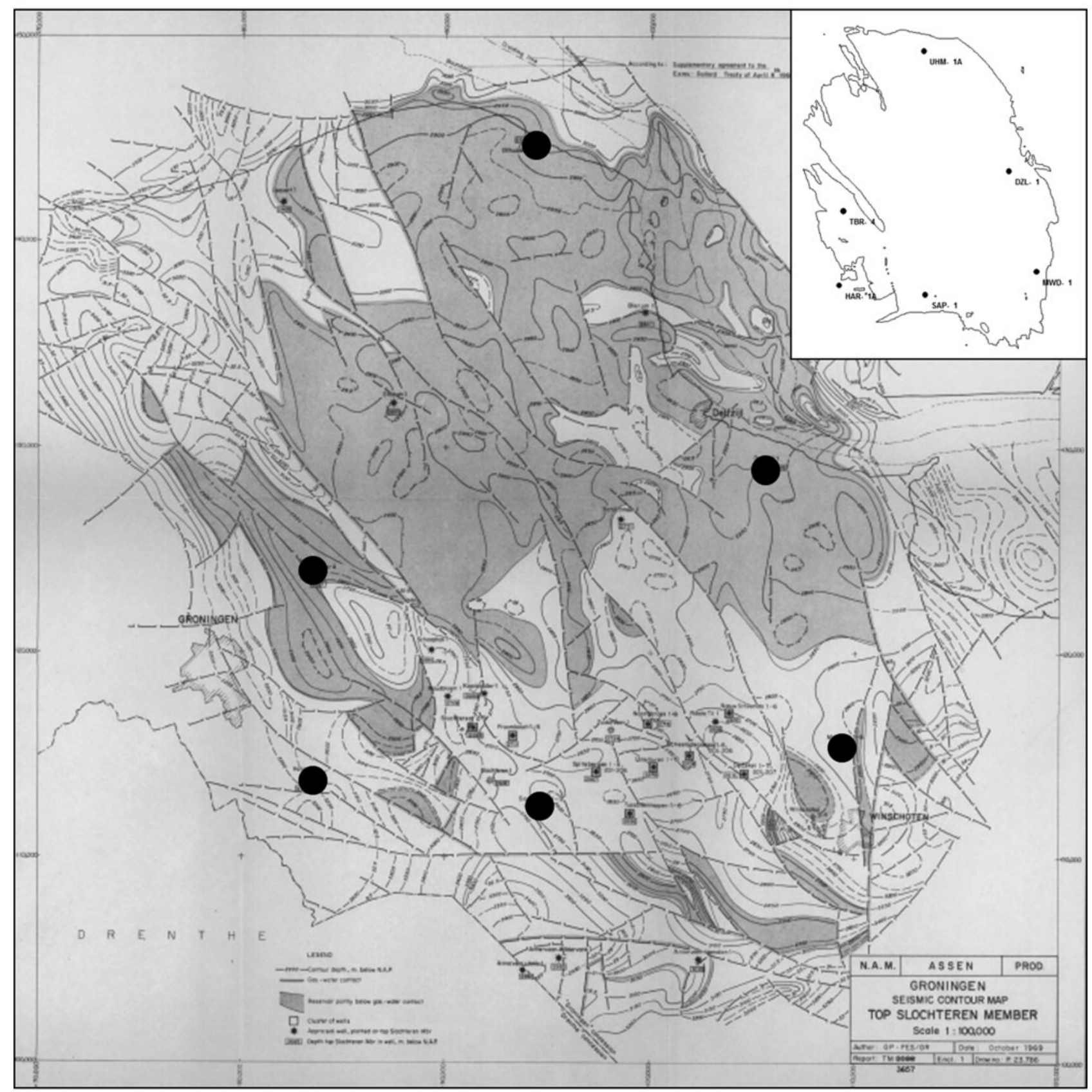

Fig. 2. Structural map of the Groningen field prepared for an internal NAM document in 1969. Map area extended compared to Figure 1 based on appraisal wells drilled in the east and north.

point in time there was no realization of the full extent of the field.

With continued appraisal and development of the field, more seismic and well data became available. In 1969, this resulted in a much-refined top_reservoir map (Fig. 2), which formed the basis for a GIIP (volume of gas initially in place) of $2730 \mathrm{bcm}$ (billion $\mathrm{m}^{3}$ ). This number was still based on a mapbased (2D) evaluation using reservoir thickness isochores and averaged properties.

Major steps forward in static modelling came from the introduction of 3D seismology and the explosive development of com- puter technology in the 1980s and 90s. This enabled building of the first full-field Groningen 3D (static/dynamic) reservoir model in 2003. This model served as a basis for development activities and reserves reporting until 2009. At that point in time, NAM was evaluating a number of major investment decisions related to the installation of second- and third-stage compression and to the development of peripheral parts of the field. It was realised that the existing dynamic model was too coarse to provide sufficient flexibility for properly evaluating the subsurface uncertainties. Moreover, the quality of the dynamic model history match was seen to deteriorate over time, leading to less reliable 


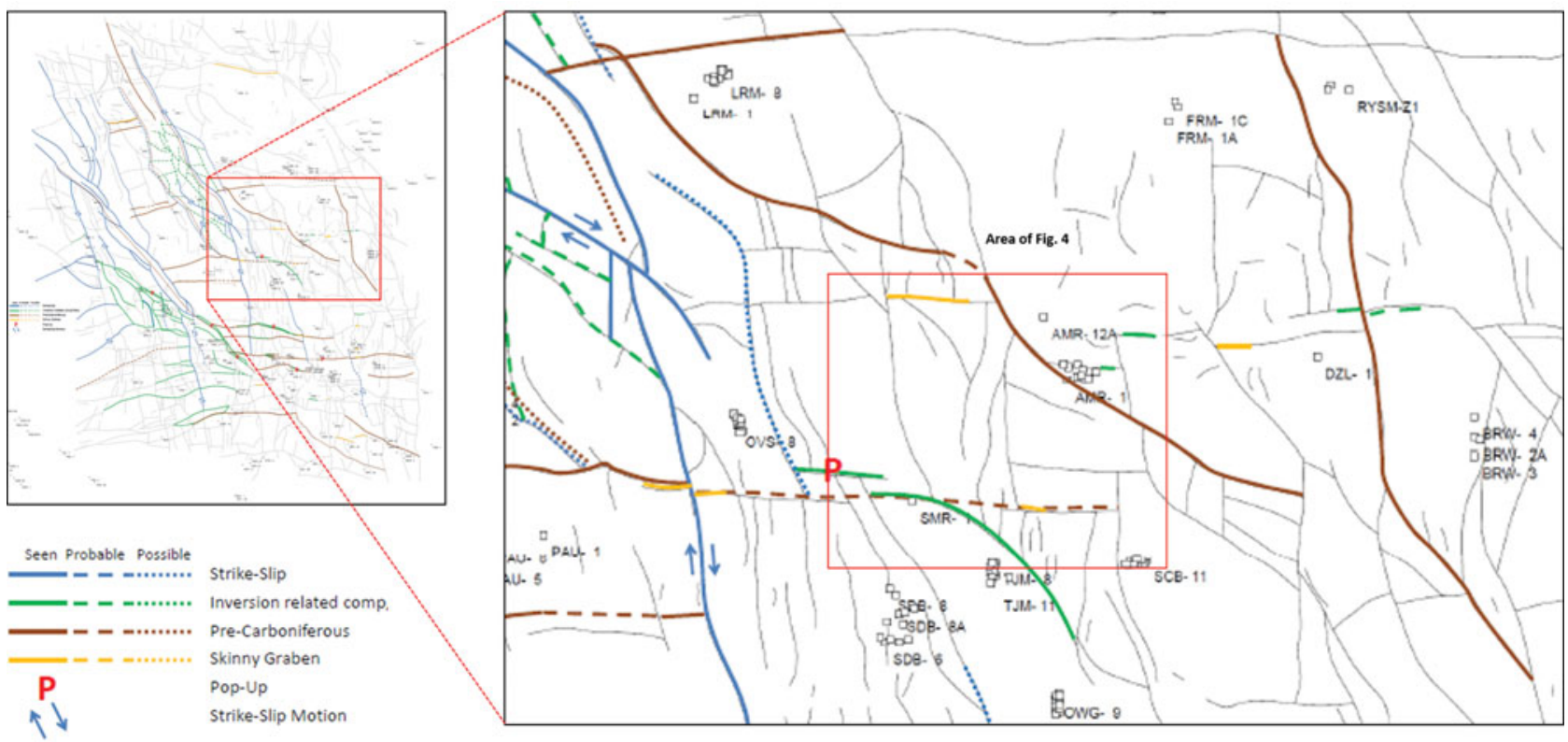

Fig. 3. Mapped faults of the Groningen field (Visser, 2012), with different fault styles indicated by colours where possible. Full-field map (left) and detailed map of central area of the field (right).

production forecasts, and consequently a less reliable basis for investment. This was the reason to start building a new generation of static and dynamic reservoir models from scratch. The rapid development of modelling techniques and software since 2003 has allowed for a higher level of sophistication with respect to model resolution, and new data and geological insights could also be incorporated. The first set of static and dynamic models of this generation was completed in early 2012. The static models are described in the following; dynamic models are the subject of a separate paper (Van Oeveren et al., 2017).

\section{Static modelling results of 2012}

The construction of the Groningen Field Review 2012 model, or GFR2012 for short, included a number of subsequent modelling steps.

The basic input for the structural framework of the Groningen reservoir models comprises a Top_Rotliegend depth attribute map and a fault model, both interpreted from seismic. The Top_Rotliegend surface is tied to the Top_Rotliegend depths that have been found in more than 400 well penetrations in the model area. More than 1100 faults have been interpreted from seismic at Top_Rotliegend level. These are shown in Figure 3 together with an interpretation of the kinematic nature of part of the faults.

The top surface and fault data were combined to construct a 3D grid. A grid cell size of $100 \times 100 \mathrm{~m}$ was chosen as a compromise between the level of geological detail and the required processing time for subsequent modelling steps. For similar reasons, the number of faults included in the grid was reduced to around 700. These were connected, extended or combined to make up a structural model consisting of 70 segments (Fig. 4). The 400 mapped faults excluded from the gridding exercise all had very limited lateral extent and throw, and are positioned inside the segments. As such, they do not affect the flow properties of the reservoir.

The Rotliegend in Groningen has been subdivided into 12 zones, based on picks from wireline logs and core, and supported by the Top_Rotliegend interpreted on seismic. The zones are further subdivided into a total of 175 reservoir layers. There are five thicker reservoir zones, separated by four thin heterolithic zones. The upper part of the section is subdivided into three clay- to silt-rich zones (Fig. 5). This zonation largely follows the stratigraphic subdivision into Lower Slochteren Sandstone, Ameland Claystone, Upper Slochteren Sandstone and Ten Boer Claystone (de Jager \& Visser, 2017). The basal onlap architecture is observed in the lowermost zones which do not extend to the south of the model area. The full 3D grid consists of approximately 6 million cells.

The last step in the construction of the static model is to assign reservoir properties to the model grid cells. The general method is based on geostatistical techniques. For a given reservoir property, wireline logs are upscaled to derive mean values for each model cell that is crossed by the well trajectories. The total distribution of all upscaled values is analysed to identify vertical and lateral trends and to derive vertical and horizontal variograms. The modelling algorithm then creates values for each grid cell by (1) honouring the upscaled log values for grid cells crossed by wells, and (2) simulating values for the interwell areas by sampling from the distribution of upscaled log data and honouring the variogram characteristics (Fig. 6). Additional 


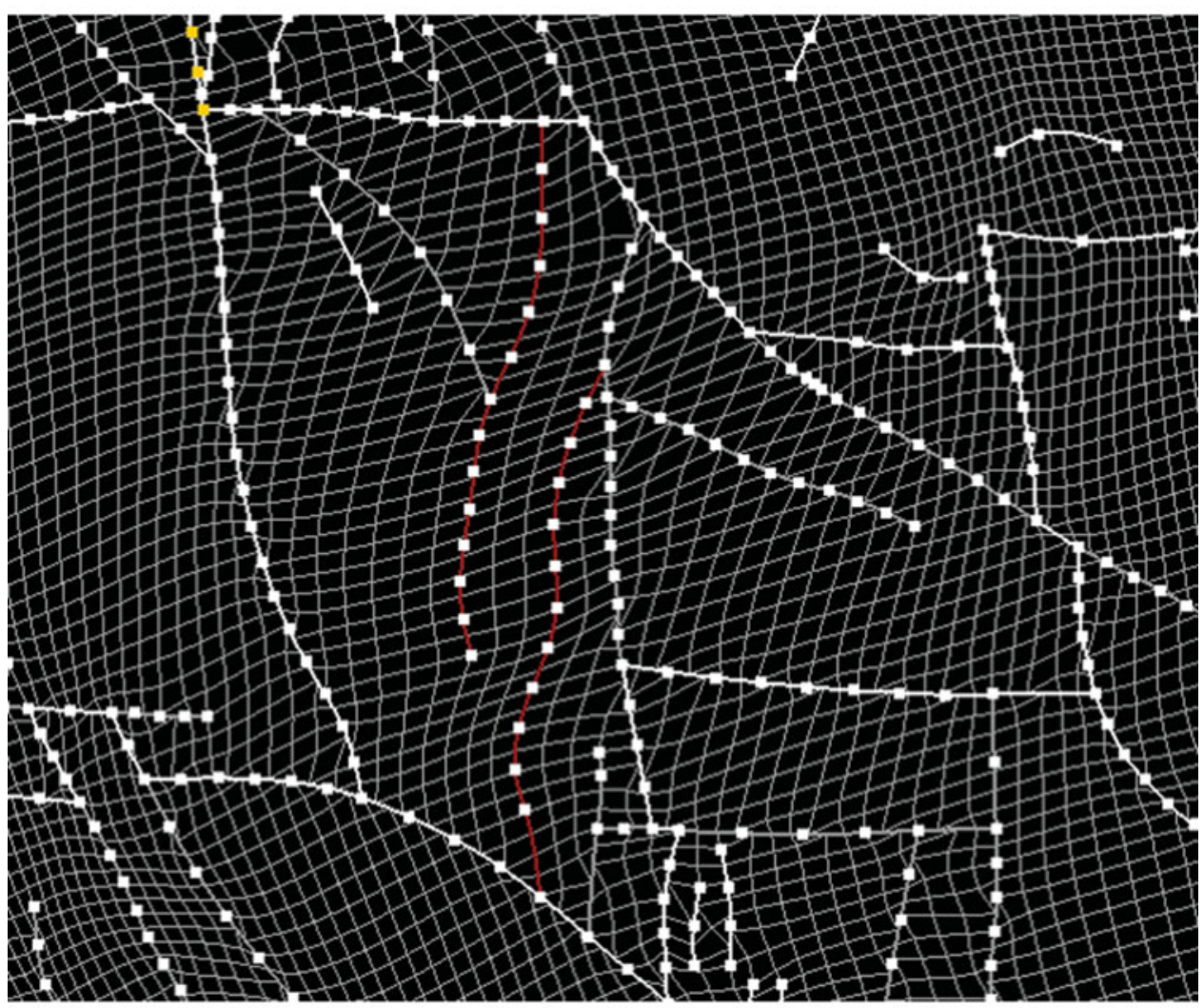

Fig. 4. Detailed view of part of the Groningen static model grid; for location see Figure 3.

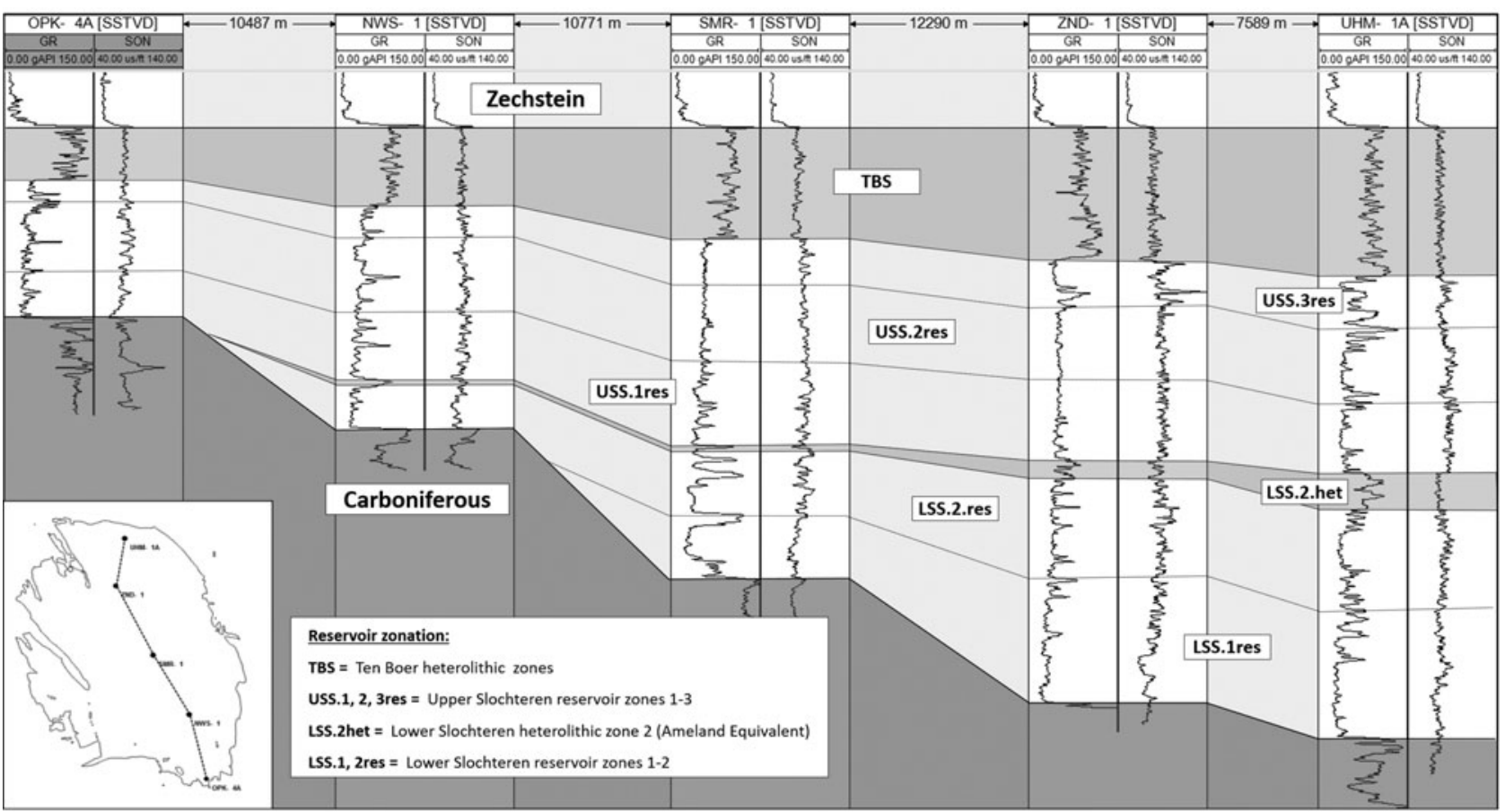

Fig. 5. SSE-NNW well correlation panel across the Groningen field, indicating the subdivision of the Rotliegend into reservoir zones. Lower Slochteren zones onlap against the Top_Carboniferous surface. 


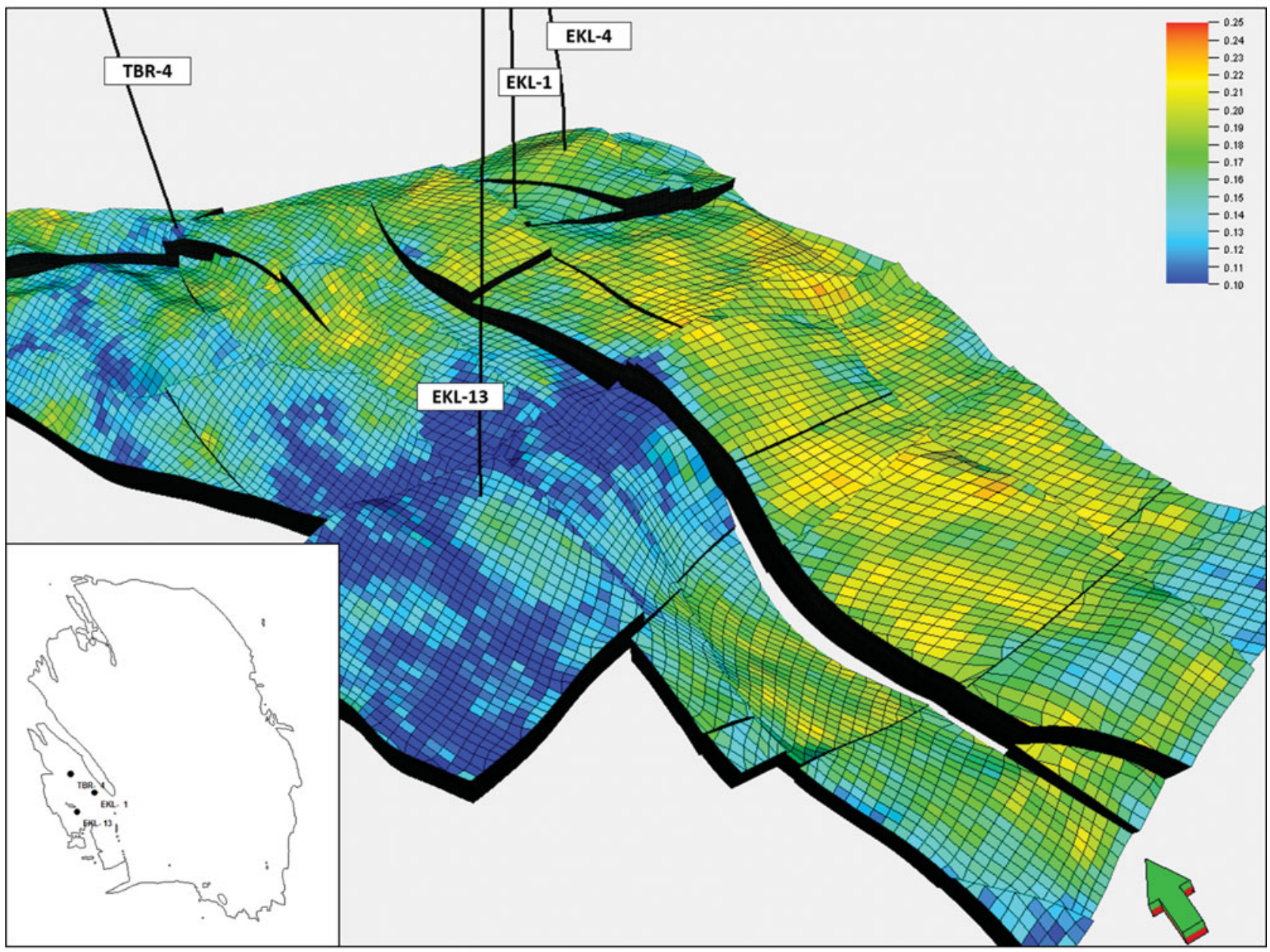

Fig. 6. Perspective view of the porosity distribution in the Eemskanaal area in the southwestern periphery of the Groningen field.

constraining of the simulations can be done with trend maps derived from other data sources, such as seismic attributes, facies models, etc. A full account of the methodologies, data and trends applied can be found in Visser et al. (2012).

Once the model cells have been assigned a set of reservoir properties (clay percentage, porosity, water saturation, permeability), it can be calculated how much gas is contained in the entire accumulation, and how that volume is divided laterally and between individual reservoir zones.

\section{New developments since 2012}

The primary objective of the GFR2012 models was to provide a framework for adequate field development and well and reservoir management. Important elements of the field development practice include production forecasting and the planning and design of new wells in the Groningen field. However, after the August 2012 seismic event at Huizinge, a completely different application area emerged, namely the understanding and management of production-induced seismicity. The static model is the first step in the chain of modelling steps described in the introduction to this paper. This kicked off a process of contin- uous improvement and fine-tuning of both static and dynamic Groningen reservoir models. A few examples of these efforts are detailed below.

In simple terms, there is a causal chain from gas production leading to pressure depletion, which in turn leads to compaction and build-up of seismic moment. Seismic moment can be released via continuous a seismic slip and via discontinuous seismic slip along faults in the reservoir. Several elements of the static model play a role in this. First, compaction is related to porosity, which triggered a renewed focus on the distribution of porosity over the field. Second, earthquakes are thought to be caused by seismic slip along intra-reservoir faults. This makes adequate mapping of faults and assessment of fault properties essential. Several efforts are ongoing to try and link observed earthquakes to specific faults or groups of faults in the subsurface.

An extensive study towards improving the Groningen static model started with a re-evaluation of all the acquired 3D seismic data in the northern Netherlands. This involved a thorough quality control of static data acquisition parameters, preprocessing, reprocessing and imaging, all implementing the latest developments in techniques and algorithms. Multiple objectives 


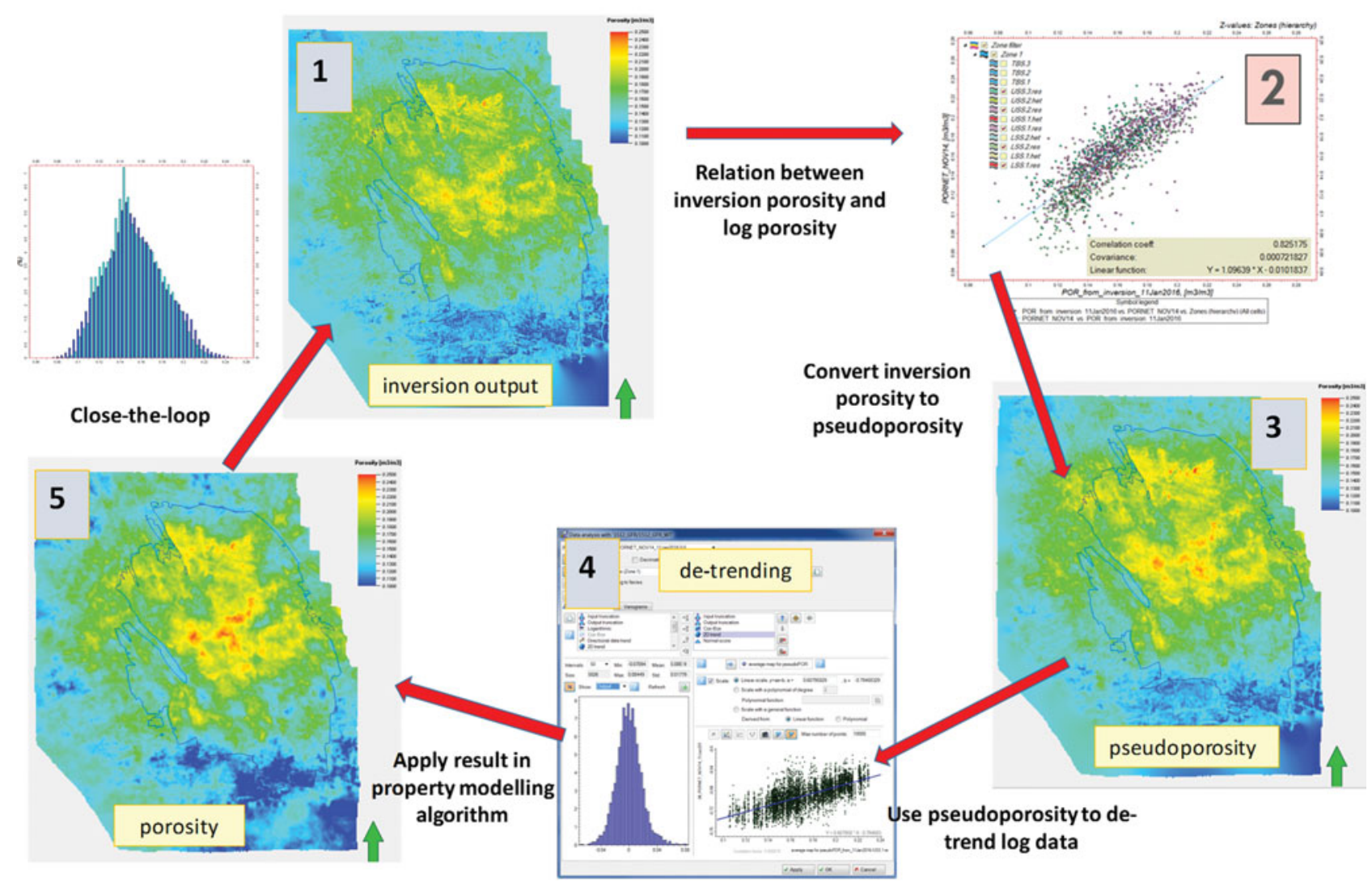

Fig. 7. Workflow for combining porosity information obtained from seismic inversion with wireline log-derived porosities to construct a detailed 3D porosity model.

were served: (1) to extend the model area to include the aquifers west and north of the Groningen field, (2) to quality-control the fault model, (3) to update the input Top_Rotliegend surface, and (4) to provide an improved seismic cube for a porosity inversion study.

Additional changes included a revised model grid, a slightly different layering architecture, and incorporation of additional input data from wells drilled since 2012.

The results have been incorporated in the reservoir models that formed the basis for the Groningen Winningsplan 2016. The fault interpretation confirmed that the existing fault model was adequate, so only minor changes were made. The same applied to the new Top_Rotliegend surface. But the inversion study delivered a porosity cube that has been used to steer petrophysical modelling algorithms away from the area of well control (Fig. 7). This has proved to be a major improvement, particularly in areas with low well density in the peripheral parts of the field and in the surrounding aquifers. Changes in the main part of the field are modest, as was to be expected. This is the area where most of the wells have been drilled and where the distribution of properties is mainly constrained by the extensive well data set. A more detailed description of the inversion work and other modelling developments is currently in preparation, and will be published on www.nam.nl upon the release of a new hazard and risk assessment towards the end of 2017.
Part II of the current paper (Van Oeveren et al., 2017) describes how this static model was taken into the dynamic realm, and used as a basis for history matching and seismic hazard and risk assessment.

\section{Future developments}

The modelling efforts described in the previous section represent the status as per early 2016, when all the input for the Groningen Winningsplan 2016 had to be completed. Since then, several activities have been initiated that may lead to further updates and refinements of the static and dynamic models. The reprocessed seismic is used to carry out a detailed mapping of the Top_Carboniferous surface. This should lead to a betterconstrained base of the Rotliegend reservoir, which in turn could lead to improved inversion results. Other activities focus on the potential effects of free gas contained in the Carboniferous in the Groningen closure, or as residual gas in the water-bearing Rotliegend intervals below the gas-water contact. Both types of gas may have an effect on the dynamic behaviour of the Groningen field. Understanding this effect may lead to improved history-matching results.

However, it should be realised that the generation of static and dynamic models generated from 2012 onwards has already proved highly adequate for reservoir management purposes. No 
significant improvements are expected in the near future, unless new developments in modelling techniques or new data become available. Nevertheless, NAM is committed to continue its endeavours to improve the models in support of studies of induced seismicity.

\section{Acknowledgements}

The authors wish to acknowledge Bart van Kempen and an anonymous reviewer for useful comments to improve the quality of this paper.

\section{References}

de Jager, J. \& Visser, C.A., 2017. Geology of the Groningen field - a review. Netherlands Journal of Geosciences / Geologie en Mijnbouw, this issue.

Van Oeveren, H.E.J., Valvatne, P., Geurtsen, L.E. \& Van Elk, J., 2017. History match of the Groningen dynamic reservoir model to subsidence data and conventional subsurface data. Netherlands Journal of Geosciences / Geologie en Mijnbouw, this issue.

Visser, C.A. (ed.), 2012. Groningen Field Review 2012 - static modelling and hydrocarbon volume determination. NAM Report No. EP201203204663. Available at www.nam.nl/feiten-en-cijfers/onderzoeksrapporten.html. 